\section{P82 IS BUSULFAN CLEARANCE DIFFERENT IN PATIENTS WITH SICKLE CELL DISEASE (SCD) COMPARED TO PATIENTS WITHOUT SICKLE CELL DISEASE?}

\begin{abstract}
1,2 $\mathrm{A} \mathrm{Remy}^{*}$, 3,4,5Y Théorêt, ${ }^{6,7} \mathrm{M}$ Ansari, ${ }^{3,8} \mathrm{H}$ Bittencourt, ${ }^{9} \mathrm{~T}$ Ducruet, ${ }^{3} \mathrm{M}$ Krajinovic, ${ }^{6,7} \mathrm{~T}$ Nava, ${ }^{3,8} \mathrm{Y}$ Pastore, ${ }^{3} \mathrm{MA}$ Rezqui, ${ }^{5,8} \mathrm{~N}$ Kleiber. ${ }^{1}$ Department of Pediatrics, Centre Hospitalier Régional de Lille, Lille, France; ${ }^{2}$ Unité de Pharmacologie Clinique, CHU SainteJustine, Montréal; ${ }^{3}$ Charles-Bruneau Cancer Center, CHU Sainte-Justine Research Center, Montreal; ${ }^{4}$ Unité de pharmacologie clinique, CHU Sainte-Justine, Montréal; ${ }^{5}$ Department of Pharmacology, CHU Sainte-Justine, Montreal, QC, Canada; ${ }^{6}$ Departement of Pediatrics, CANSEARCH Research Laboratory; ${ }^{7}$ Department of Pediatrics, Onco-Hematology Unit, University Hospital of Geneva, Geneva, Switzerland; ${ }^{8}$ Department of Pediatrics; ${ }^{9}$ Applied Clinical Research Unit, CHU Sainte-Justine, Montreal, QC, Canada
\end{abstract}

\subsection{6/archdischild-2019-esdppp.120}

Background Haematopoietic stem cell transplantation (HSCT) is the only current curative treatment for Sickle Cell Disease (SCD), with potential life-threatening consequences. Busulfan is an alkylating agent used in HSCT conditioning regimen. Because of its narrow therapeutic window, determining the optimal first dose a priori remains a challenge.

Busulfan is metabolized in the liver by conjugation with glutathione, which is catalyzed by Glutathione-S-Transferases (GSTs). GSTA1 is a known determinant of Busulfan clearance $^{12}$ (just like age and weight) suggesting that those characteristics should be known a priori to adjust the first dose of Busulfan.

Haemoglobinopathies (SCD and thalassemia) are not associated with changes in Busulfan clearance in a recent study. ${ }^{3}$ However, SCD is known to alter pharmacokinetics of other drugs. ${ }^{4}$ As it leads namely to liver dysfunction ${ }^{6}$ it may affect busulfan pharmacokinetics independently from genetic or anthropometric factors.

Our aim is to compare the clearance of the first dose of $\mathrm{Bu}$ between patients with and without SCD, considering other constitutional factors.

Methods Patients with SCD were paired to patients without SCD on known Busulfan clearance's covariates including GSTA1 group, age and frequency of administration.

Data were collected retrospectively from the HSCT Unit database at Sainte-Justine Hospital and also used in previous

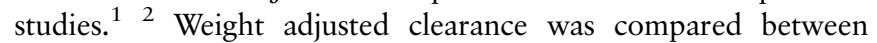
the two paired groups using a mixed procedure on SAS software.

Results Among the 129 patients included, 16 had SCD. Each patient was matched with up to 4 controls (total of 50 controls). Mean weight adjusted clearance was $3.04 \mathrm{ml} / \mathrm{min} / \mathrm{kg}$ [SD:0,18] in patients with SCD versus $3.11 \mathrm{ml} / \mathrm{min} / \mathrm{kg}$ [SD:0,14] in controls (difference $0.07 \mathrm{ml} / \mathrm{min} / \mathrm{kg} \quad \mathrm{F}=0,14$ $\mathrm{p}>\mathrm{F}=0.714$ ).

Conclusions The diagnosis of SCD did not reveal to influence independently the clearance of the first dose of Bu. Consequently, no dose tailoring is needed in those patients only by the fact of being affected by SCD.

\section{REFERENCES}

1. Ansari M, Curtis PH-D, Uppugunduri CRS, Rezgui MA, Nava T, Mlakar V, et al. GSTA1 diplotypes affect busulfan clearance and toxicity in children undergoing allogeneic hematopoietic stem cell transplantation: a multicenter study. Oncotarget 2017 Oct 31;8(53).

2. Nava T, Kassir N, Rezgui MA, Uppugunduri CRS, Curtis PH-D, Duval M, et al. Incorporation of GSTA1 genetic variations into a population pharmacokinetic model for IV busulfan in paediatric hematopoietic stem cell transplantation. British Journal of Clinical Pharmacology. 84(7):1494-504.

3. McCune JS, Baker KS, Blough DK, Gamis A, Bemer MJ, Kelton-Rehkopf MC, et al. Variation in prescribing patterns and therapeutic drug monitoring of intravenous busulfan in pediatric hematopoietic cell transplant recipients. Journal of Clinical Pharmacology. 2013 Mar;53(3):264-75.

4. Maksoud E, Koehl B, Kaguelidou F, et al. Population Pharmacokinetics of Cefotaxime and Dosage Recommendations in Children with Sickle Cell Disease. Antimicrob Agents Chemother 2018 Apr;62(4).

5. Dampier CD, Setty BN, Logan J, Ioli JG, Dean R. Intravenous morphine pharmacokinetics in pediatric patients with sickle cell disease. J Pediatr 1995 Mar;126 (3):461-7.

6. Gremse DA, Fillingim E, Hoff CJ, Wells DJ, Boerth RC. Hepatic function as assessed by lidocaine metabolism in sickle cell disease. J Pediatr 1998 Jun;132 (6):989-93.

Disclosure(s) Nothing to disclose

\section{P83 CYP2D6 PHENOTYPING IN CHILDREN TREATED WITH TRAMADOL AT THE EMERGENCY DEPARTMENT}

${ }^{1} \mathrm{~F}$ Rodieux*, ${ }^{1} \mathrm{~F}$ Storelli, ${ }^{2} \mathrm{~S}$ Manzano, ${ }^{2} \mathrm{~A}$ Gervaix, ${ }^{3} \mathrm{~K}$ Posfay-Barbe, ${ }^{1} \mathrm{C}$ Samer, ${ }^{1} \mathrm{Y}$ Daali, $1 \mathrm{~J}$ Desmeules. ${ }^{1}$ Division of Clinical Pharmacology and Toxicology, Department of Anaesthesiology, Pharmacology, Intensive Care and Emergency Medicine; 'Division of Paediatric Emergency Medicine, Child and Adolescent Department; ${ }^{3}$ Paediatric Infectious Diseases Unit, Department of Paediatrics, Geneva University Hospitals, Geneva, Switzerland

\subsection{6/archdischild-2019-esdppp.121}

Background Pain management is essential and opioids side effects are of major concern. Tramadol safety and efficacy is influenced by CYP2D6 activity. Phenotyping measurement is available to assess CYP2D6 activity and allow a safe precision medicine approach. ${ }^{4}$ However need for administration of a probe drug and invasive sampling limit its use. Our objective is to evaluate direct measurement of M1/tramadol ratio and pupillometry as phenotyping methods to identify CYP2D6 ultrarapid (UM) and poor (PM) metabolizers in children treated with tramadol. ${ }^{1-6}$

Methods We plan to include 53 children receiving their 1st dose of tramadol at the Emergency Department (ED) of the Geneva Children's Hospital. Children with concomitant inhibitors/inducers of CYP2D6 and CYP3A or drug with an impact on pupil size are exclude. Standard CYP2D6 phenotyping is performed by measuring blood dextrorphan/dextromethorphan (DOR/DEM) using dried blood spots (DBS) at least 90min after dextromethorphan and tramadol administration. Tramadol and its active metabolite, M1, concentrations are also performed using DBS at the same time. Pupillometry is performed at time of tramadol administration and 1 to twice per hour, during the stay in the ED.

Results We included 26 children, median age 10.7 years, of which 2 are UM (8\%) and 3 PM (12\%), corresponding to what is expected in the Caucasian population. We found a positive correlation between DOR/MED and M1/tramadol ratio $\left(\mathrm{R}^{2}=0.389, \mathrm{p}=0.0006\right)$. Pupillometry analyses are in progress. Tramadol $2 \mathrm{mg} / \mathrm{kg}$ orally was well tolerated in all children, including UM and PM.

Conclusion Our study shows that it is possible to determine CYP2D6 activity in order to provide safe and effective tramadol prescription in children in a less invasive manner than by administering a probe drug, by directly determining the metabolic ratio between tramadol and its metabolite, M1 in children treated with tramadol

\section{REFERENCES}

1. Fliegert, F., B. Kurth, and K. Gohler, The effects of tramadol on static and dynamic pupillometry in healthy subjects-the relationship between pharmacodynamics, pharmacokinetics and CYP2D6 metaboliser status Eur J Clin Pharmacol, 2005. 61(4): p. 257-66. 
2. Slanar, O., et al., CYP2D6 polymorphism, tramadol pharmacokinetics and pupillary response Eur J Clin Pharmacol, 2006. 62(1): p. 75-6; author reply 77-8.

3. Slanar, O., et al., Miotic action of tramadol is determined by CYP2D6 genotype Physiol Res, 2007. 56(1): p. 129-36.

4. Kirchheiner, J., et al., Effects of the CYP2D6 gene duplication on the pharmacokinetics and pharmacodynamics of tramadol I Clin Psychopharmacol, 2008. 28(1): p. $78-83$.

5. Matouskova, O., et al., Pupillometry in healthy volunteers as a biomarker of tramadol efficacy J Clin Pharm Ther, 2011. 36(4): p. 513-7.

6. Connelly, M.A., et al., Pupillometry: a non-invasive technique for pain assessment in paediatric patients Arch Dis Child, 2014. 99(12): p. 1125-31.

Disclosure(s) Nothing to disclose

\section{P84 PEDIATRIC ONCOLOGY STUDIES TRIGGERED BY THE UNITED STATES (US) FOOD AND DRUG ADMINISTRATION (FDA) AND THE EUROPEAN UNION (EU) EUROPEAN MEDICINES AGENCY (EMA) AIM AT LABELS, NOT AT IMPROVED TREATMENT. SOME HARM YOUNG PATIENTS BY EXPOSING THEM TO SUBSTANDARD MONOTHERAPY INSTEAD OF COMBINATION TREATMENT}

K Rose*. Medical Science, Klausrose Consulting, Riehen, Switzerland

\subsection{6/archdischild-2019-esdppp.122}

Background Both FDA and EMA reward/demand pediatric oncology studies. Do they advance pediatric cancer care?

Methods We analysed publications of FDA representatives, ${ }^{1-3}$ FDA-triggered pediatric oncology studies in the literature and in www.clinicaltrials.gov, ${ }^{4}$ and FDA/EMA pediatric reports. ${ }^{5-6}$ Results FDA authors express two key assumptions: (1) children, defined as $<17 y$, need separate proof of efficacy; ${ }^{1-3}$ (2) with the exception of chronic myelogenous leukema, the biology of cancer in children is different from adult cancer. ${ }^{1}$ FDA-triggered studies investigated single cytoxics agents in heavily pretreated refractory/relapsed patients $\leq 21 \mathrm{y}^{2}{ }^{4}$ In these days, combination treatment with up to 13 cytotoxic agents was standard of care. ${ }^{7}$ Another round of treatment with a single chemotherapy agent did not increase survival, but rewarded companies with patent extension, researchers with publications, the FDA with labeled information. The EU expanded the definition of children to $<18 \mathrm{y}$ and demands 'pediatric investigation plans' (PIPs) also for rare diseases. One FDA-triggered package investigated ipilimumab in 'pediatric' melanoma; 13 EMA PIPs demand 'pediatric' studies in solid tumors including melanoma; two 'pediatric' monotherapy studies with ipilimumab and vemurafenib, respectively, were terminated in 2016, five others continue recruiting. ${ }^{3} 48$

Discussion FDA/EMA-requested/demanded 'paediatric' oncology studies focus on labels in administratively defined 'children'. FDA/EMA-used age limits are not physiological. FDA assumptions about different biology of 'pediatric' malignancies are

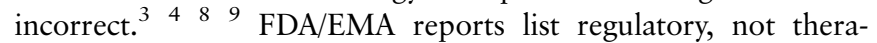
peutic achievements. ${ }^{5-6}$ Some EU researchers perform predominantly PIP-demanded oncology studies. In a cartel-like cooperation, the EMA demands such studies, threatening nonapproval of life-saving drugs. Researchers and EMA representatives co-author lauding reports. ${ }^{10}$

Conclusion FDA representatives augmented the flawed 'therapeutic orphans' concept by additional wrong assumptions about 'paediatric' malignancies' biology. ${ }^{1-4}$ The EMA further expanded the 'Paediatric Imperative'. Also PIPs do not advance treatment. Ethics committees should be alerted to re- analyze ongoing 'pediatric' studies, suspend questionable ones, and reject new ones. US+EU pediatric laws need revision.

\section{REFERENCES}

1. Snyder KM, et al. The impact of the written request process on drug development in childhood cancer Pediatr Blood Cancer. 2013;60:531-537.

2. Wharton GT, et al. Impact of pediatric exclusivity on drug labeling and demonstrations of efficacy Pediatrics. 2014;134(2):e512-e518.

3. Roberts $R$, et al. Pediatric Drug Labeling. Improving the Safety and Efficacy of Pediatric Therapies JAMA. 2003;290(7):905-911.

4. Rose K, Grant-Kels JM. Pediatric Melanoma - The Whole (Conflicts Of Interest) Story Int I Womens Dermatol 2018

5. FDA. Best Pharmaceuticals for Children Act and Pediatric Research Equity Act. July 2016. Status Report to Congress Department of Health and Human Services.

6. EMA. 10-year Report to the European Commission. General report on the experience acquired as a result of the application of the Paediatric Regulation.

7. Norris RE, Adamson PC. Challenges and opportunities in childhood cancer drug development Nat Rev Cancer. 2012 Nov;12(11):776-82.

8. Rose K, Walson PD. Are Regulatory Age Limits in Pediatric Melanoma Justified? Curr Ther Res Clin Exp. 2019

9. Pappo AS. Pediatric melanoma: the whole (genome) story. Am Soc Clin Oncol Educ Book. 2014:e432-5.

10. Ruperto $\mathrm{N}$ et al. A European Network of Paediatric Research at the European Medicines Agency (Enpr-EMA). Arch Dis Child. 2012 Mar;97(3):185-8.

Disclosure(s) The author has worked for more than 20 years in research \& development/medical affairs in pharma $\neg$ ceutical industry and is now an independent consultant, advising pharmaceutical companies and academic institutions in all aspects of pediatric drug development, organizing scientific conferences, publishing, \& more. The author's elder daughter is severely handicapped with a rare syndrom, which has biased him against empty governmental promises.

\section{P85 PREDICTION OF RALTEGRAVIR PLASMA CONCENTRATION IN HIV PAEDIATRIC PATIENTS USING PHYSIOLOGICALLY-BASED PHARMACOKINETIC MODEL}

F Salem* ${ }^{*}$ K Abduljalil, T Johnson. Certara UK Limited, Simcyp Division, Sheffield, UK

\subsection{6/archdischild-2019-esdppp.123}

Background Raltegravir is a drug used to treat patients with HIV infection. Understanding the disposition kinetics including the ontogeny of the major metabolic enzyme (UGT1A1) is important in prediction of raltaeravir pharmacokinetics in paediatric patients.

Methods Sim-Raltegravir compound file in Simcyp simulator version 18 was used to predict pharmacokinetics in paediatric subjects aged 4 weeks to 6 months, 0.5 to 2,2 to 6 and 6 to 12 years. Details of trial design were matched as closely as possible with a clinical study. ${ }^{1}$ Rate of absorption and variability in first order absorption model within Simcyp were set to the reported values. Predicted plasma concentration time profiles with 5 th and 95th percentile were compared with observations.

Results The predicted vs. observed geometric mean area under plasma concentration-time profile of raltegravir was 18.4 vs. $22.3 \mu \mathrm{M} . \mathrm{h}$ in subjects 4 weeks to 6 months and 16.5 vs. $19.8 \mu$ M.h in those 0.5 to 2 years old. In 2 to 6 and 6 to 12 year olds around $80 \%$ and $85 \%$ of observed data were within 5 th and 95 th percentile of the predictions.

Conclusion The results show that the UGT1A1 ontogeny profile in the Simcyp version 18 adequately addressed age-related differences in pharmacokinetics of raltegravir.

\section{REFERENCE}

1. Rizk, M., et al, J Clin Pharmacol 2015; 55(7):748-56 